\title{
Analysis of flexibility factors in Sustainable Supply Chain using Total Interpretive Structural Modeling (T-ISM) Technique
}

\author{
Sandeepa $^{a}$ and Mahesh Chand ${ }^{b^{*}}$
}

\author{
${ }^{a}$ Assistant Professor, Mechanic
Faridabad- 121004 , India
${ }^{b}$ Assistant Professor Mechani \\ C H R O N I C L E \\ Article history: \\ Received December 2, 2016 \\ Received in revised format \\ December 10,2016 \\ Accepted June 162017 \\ Available online \\ June 172017 \\ Keywords: \\ Sustainable supply chain \\ management (SSCM) \\ Flexibility \\ TISM
}

\section{Introduction}

Supply chain management (SCM) is an effective methodology through which links between the factors established and the production of the company is increased with the reduction of cost. This gives rise to the adoption of supply chain management in different sectors (Pramod \& Banwet, 2010). Research on supply chain management has evolved from its origins as a promising field of study to encompass construct definition, identification of the field's central issues, and establishment of its conceptual boundaries (Helmuth et al., 2015; Amalnic \& Saffar, 2017). The multiple flexibility options in supply chain planning help to manage the usual operations efficiently and effectively, whilst improve the supply chain (SC) resiliency in response to inherent environmental uncertainties (Esmaeilikia et al., 2016). Tavana et al. (2016) identified three levels of supply chain including supplier, manufacturer and distributer for performance evaluation. Supply chain management has different issues at different levels which affects the supply chain like risk management, operational management, supplier related issues,

* Corresponding author

E-mail address: mchanddce@gmail.com (M. Chand)

(C) 2018 Growing Science Ltd. All rights reserved. doi: $10.5267 /$ j.uscm.2017.6.006 
market related issues, performance measurement and sustainability etc. In today's market environment, sustainability in supply chain is one of the most important issues, which attracts the researchers in this domain.

Sustainable supply chain management can be regarded as the improved management of supply chain regarding social, economic and environmental issues. Through the combination of these issues, supply chain management plays an important role both in production and environmental management (Salmona et al., 2010). The sustainable supply chain management reduces the cost of the product, increases the customer's satisfaction, increases the sales of the product and therefore increases the overall efficiency of the firms. Sustainable supply chain management is more effective if the production is flexible. Flexibility plays an important role for the smooth of production system. Flexibility in sustainable supply chain management is essential for industries to achieve social, economic and environmental issues. Today flexibility is not restricted only to the machining parts, but in every phase of a manufacturing process from supplier to manufacturer (Rao \& Parnichkun, 2009; Shayan \& Liu, 1995). To produce products of good quality and fulfill customer's needs, production industries have to adapt sustainable flexibility in their manufacturing systems. Today industries are focusing on quality and variety than on quantity (Dubey \& Ali, 2014). To beat competition in market, industries have to be responsive and adaptable. That is why, according to the market needs, industries realize the need for flexibility in sustainable supply chain management. Regarding this, some factors related to flexibility in sustainable supply chain management have been identified through literature review and establish a relationship among these factors. For this purpose, techniques are available in literature are Interpretive Structural Modeling (ISM), Total Interpretive Structural Modeling (T-ISM) and Weighted Interpretive Structural Modeling (W-TSM). The extended version of ISM used in literature is W-ISM in which an effective index of factors with their numeric value has been carried out (Chand et al., 2014; 2015). Whereas enlisted in literature T-ISM has been used to model and structure with greater understanding and interplay of factors as compared with ISM (Sushil, 2005; 2012a; 2012b; Srivastava \& Sushil, 2014; Khatwant et al., 2015; Kausar et al., 2017). In this paper, TISM technique has been utilized to fulfill the key objectives which are as follows:

- To identify and rank flexibility factors in sustainable supply chain,

- To develop a relationship among the flexibility factors using T-ISM and

- To analyze and discuss the administrative implication.

The rest of paper is organised as follows. Section 2 deals with literature review. Section 3 presents solution methodology and demonstration of solution methodology is presented in Section 4. Section 5 presents results and discussion. In section 6 and section 7, conclusion and future directions and finally limitations are presented.

\section{Literature review}

In literature review on flexibility, no definition on flexibility that is accepted worldwide is determined. Much more attention has been given only on production flexibility. Flexibility is the organization's ability to meet an increasing variety of customer expectations without excessive costs, time, organizational disturbances, or performance losses (Upton 1994; 1995). Wadhwa and Rao (2004) presented a framework for understanding flexibility in supply chains. Elcio and Cristina (2007) defined supply chain flexibility as the ability to react to environmental uncertainty with time, effort and cost. Karen et al. (2012) considered supply chain flexibility as a second-order factor model consisting of four dimensions, i.e. sourcing flexibility, operating system flexibility, distribution flexibility and information system flexibility. According to Zang and Awashti (2014) sustainable supply chains is the need of modern times. In order to make them successful, listening to voice of the customer and integrating them in the design and development phases of supply chains are very important. Beske and Seuring (2014) explored orientation, continuity, collaboration, risk management and proactivity are the keys for the achievement of sustainable supply chain. Bottani et al. (2015) analyzed the impact of 
machine flexibility in supply chain performance, which includes economic parameters, supply chain lead time and bullwhip effect. Esmaeilikia et al. (2016) identified tactical SC flexibility measures and options for development of flexible SC planning models. On the basis of the literature and discussions with the industrial and academia experts, some flexibility factors in sustainable supply chain management (SSCM) are identified and used for analysis. Descriptions of these factors are as follows:

- Product flexibility: Product flexibility is related to produce product according to customer's requirement different variety (Goyal, 2007).

- Sourcing flexibility: In sourcing flexibility, an alternate supplier is kept for reserve to fulfill the components and raw material requirements (Gosling et al., 2008; Borhanazad \& Tran, 2012)

- Routing flexibility: The routing flexibility of the product can be produced by using varying routes through flexible transport, many different machines and reduces negative impact on sustainable supply chain management.

- Trans-shipment flexibility: It involves the supply of products to the demand locations at minimum cost by using the transport efficiently by covering the maximum routes in one time by keeping in view the effect of transshipment flexibility in SSCM.

- Delivery flexibility: Delivery flexibility means to provide the delivery facility to the customer. It is the capability of the company to provide the product at the required time, in the right quantity at the right place.

- Distribution flexibility: Distribution flexibility means to provide the product to the customer's in any situation, product should be reached at the appropriate time.

- Responsiveness flexibility: Responsiveness flexibility means respond to target market needs immediately.

- Postponement flexibility: In postponement flexibility, product can be stored for long time for the future requirement without any loss in the basic form and quality of the product.

- Waste and Recycling flexibility: This is one of the most important flexibility in SSCM. It is related to recycle the product which can be used for the new production of the product. It reduces negative impacts sustainable supply chain.

- Natural resource flexibility: It is also the important flexibility in SSCM. It involves the production of the components with the utilization of natural resources to the impact on sustainability and the cost of the product can be minimized.

- Launch flexibility: Launch flexibility means to launch new product in the market with the product varieties. It makes the change in the entire sustainable supply chain.

The identified flexibilities play an effective role in sustainable SCM. These are several essentials factors for the management of flexibility in SSCM. Sustainable flexibility is an attribute of a system technology for coping with the variety of its environmental needs. Sustainable flexibility reflects the ability of a system to change or react with little penalty in time, effort, cost or performance (Xiao \& Yuming, 2014). For the analysis and intersections between flexibility factors T-ISM technique has been utilized. TISM is advancement of interpretive structural modeling technique, and is used to model and structure the factors for greater understanding of the interaction of these factors (Sushil, 2005a; 2005b; 2012). In literature T-ISM has been utilized by many researchers. Nasim (2011) used TISM technique to model and structure the forces of change and continuity in e-government. Prasad and Suri (2011) applied TISM to model continuity and change forces in private higher technical education. Wasuja et al. (2012) used TISM to create a hierarchy amongst the various factors of cognitive bias in selling specialty drugs and interpret the relationships amongst them. TISM was used to model strategic performance factors for effective strategy execution (Srivastava \& Sushil, 2013; Sandbhor \& Botre, 2014). Mangla et al. (2014) purposed TISM based model to evaluate the causality and illustrate factors with interpretation of relationships via directed links in the form of interpretive matrix, and suggested that the factors at the bottom level were crucial for sustainability focused chain to build its capability on risks and risk issues. Khtwani et al. (2015) used TISM for group decision making. Jain and Raj (2015) used TISM 
for modeling and analysis of FMS flexibility factors. They identified 15 flexibility factors and analyzed their driving and dependence powers on the basis of fuzzy-MICMAC analysis. From the review of literature, researchers have not come across to utilize TISM for analyzing the flexibility factors in sustainable supply chain management.

\section{Solution Methodology}

In T- ISM technique, the reachability matrix and its partitions are evaluated which are adopted as it is in the process of ISM. The basic processes of T-ISM adopted by researchers are as follows.

Step I: Identify and define elements: The first step in any structural modeling is to identify and define the elements whose relationships are to be modeled. In the context of this paper, the forces of change and continuity are the elements which are identified from the literature and in consultation with domain experts.

Step II: Define contextual relationship: In order to develop the model of the structure relating the factors, it is crucial to state the contextual relationship among the factors. Expert inputs are solicited to capture the contextual relationship among the factors.

Step III: Interpretation of relationship: This is the first step forward over the traditional ISM. Though ISM too captures the contextual relationship, it remains silent on how that relationship really works.

Step IV: Interpretive logic of pair-wise comparison: In ISM, the elements are compared to develop SSIM (Self Structural Interaction Matrix), the interpretation of which indicates direction of the relationship only. ISM makes use of the concept of interpretive matrix to fully interpret each paired comparison by answering the interpretive query as mentioned in step III. For paired comparison, the $i t h$ element is compared individually to all the elements from $(i+1)$ th to the $n t h$ element. For each link the entry could be 'Yes(Y)' or ' $\mathrm{No}(\mathrm{N})$ ' and if it is 'Yes', then the reason is to be provided. This reveals the interpretive logic of the paired relationships in the form of 'Interpretive Logic - Knowledge Base' (Sushil, 2009).

Step V: Reachability matrix and transitivity check: The paired comparisons in the interpretive logic - knowledge base are translated in the form of reachability matrix by making entry 1 in $i-j$ cell, if the corresponding entry in knowledge base is ' $\mathrm{Y}$ ', or else it should be entered as 0 for the corresponding entry ' $\mathrm{N}$ ' in knowledge base. This matrix is checked for the transitivity rule and updated till full transitivity is established.

Step VI: Level Partition on reachability matrix: The level partition is carried out similar to ISM to know the placement of elements level-wise (Warfield, 1974; Saxena et al., 2006). Determine the reachability and antecedent sets for all the elements. The intersection of the reachability set and the antecedent set will be the same as the reachability set in case of the elements in a particular level. The top level elements satisfying the above condition should be removed from the element set and the exercise is to be repeated iteratively till all the levels are determined.

Step VII: Developing diagraph: The elements are arranged graphically in levels and the directed links are drawn as per the relationships shown in the reachability matrix. A simpler version of the initial diagraph is obtained by eliminating the transitive relationships step-by-step by examining their interpretation from the knowledge base. Only those transitive relationships may be retained whose interpretation is crucial.

Step VIII: Interaction matrix: The final diagraph is translated into a binary interaction matrix form depicting all the interactions by 1 entry. The cells with 1 entry are interpreted by picking the relevant interpretation from the knowledge base in the form of interpretive matrix.

Step IX: Total interpretive structural model: The information contained in the interpretive matrix and the diagraph is used to obtain the TISM. The nodes in the diagraph are replaced by the element definition and are placed in boxes. The interpretation in the cells of interpretive matrix is depicted by the side of the respective links in the structural model. This leads to total interpretation of the structural model in terms of the interpretation of its nodes as well as links. 


\section{Demonstration of solution methodology}

In the first step the model has been developed by the judgment of academicians and experts in the field of supply chain management. By brainstorming with various executives of different companies and academicians, the relationships among flexibility factors have been identified.

Table 1

Rank distribution

\begin{tabular}{llll}
\hline S. No & Factors & Mean Score & Rank \\
\hline 1 & Product flexibility & 3.86 & 1 \\
2 & Sourcing flexibility & 3.71 & 2 \\
3 & Routing flexibility & 3.62 & 3 \\
4 & Trans-shipment flexibility & 3.41 & 4 \\
5 & Delivery flexibility & 3.39 & 5 \\
6 & Distribution flexibility & 3.2 & 6 \\
7 & Responsiveness flexibility & 3.09 & 7 \\
8 & Postponement flexibility & 2.96 & 8 \\
9 & Waste \& Recycling flexibility & 2.77 & 9 \\
10 & Natural resource flexibility & 2.64 & 10 \\
11 & Launch flexibility & 2.49 & 11 \\
\hline
\end{tabular}

Next step is to develop a Structural Self-Interaction Matrix (SSIM) which shows the direction of contextual relationships among the elements by symbolic interactions (Table-2). Regarding this, the four symbols are used for matrix formation. In which

FD (Forward direction): Factor $i$ direct to factor $j$

$\mathrm{BD}$ (Backward direction): Factor $j$ direct to factor $i$

$\mathrm{RD}$ (Reverse direction): Factor $i$ and $j$ will direct to each other.

UD (Unrelated direction): Factors $i$ and $j$ are undirected.

Using above notations (i.e. FD, BD, RD, UD) SSIM have been derived.

Table 2

Structural Self-Interaction Matrix (SSIM)

\begin{tabular}{|c|c|c|c|c|c|c|c|c|c|c|c|c|}
\hline S. No. & Factors & 11 & 10 & 9 & 8 & 7 & 6 & 5 & 4 & 3 & 2 & 1 \\
\hline 1 & Product flexibility & UD & FD & FD & UD & FD & UD & $\mathrm{BD}$ & FD & FD & $\mathrm{RD}$ & $\mathrm{RD}$ \\
\hline 2 & Sourcing flexibility & $\mathrm{BD}$ & FD & FD & UD & BD & UD & FD & RD & UD & \multirow{10}{*}{$\mathrm{RD}$} & \\
\hline 3 & Routing flexibility & UD & UD & UD & FD & FD & FD & $\mathrm{RD}$ & FD & $\mathrm{RD}$ & & \\
\hline 4 & Trans-shipment flexibility & UD & UD & UD & UD & $\mathrm{BD}$ & $\mathrm{BD}$ & $\mathrm{BD}$ & \multirow[t]{8}{*}{ RD } & & & \\
\hline 5 & Delivery flexibility & UD & UD & UD & UD & FD & $\mathrm{RD}$ & $\mathrm{RD}$ & & & & \\
\hline 6 & Distribution flexibility & UD & UD & UD & $\mathrm{BD}$ & FD & \multirow[t]{6}{*}{$\mathrm{RD}$} & & & & & \\
\hline 7 & Responsiveness flexibility & FD & FD & FD & FD & FD & & & & & & \\
\hline 8 & Postponement flexibility & UD & UD & UD & \multirow[t]{4}{*}{$\mathrm{RD}$} & & & & & & & \\
\hline 9 & Waste and recycling flexibility & UD & $\mathrm{BD}$ & $\mathrm{RD}$ & & & & & & & & \\
\hline 10 & Natural resource flexibility & UD & \multirow[t]{2}{*}{$\mathrm{RD}$} & & & & & & & & & \\
\hline 11 & Launch flexibility & $\mathrm{RD}$ & & & & & & & & & & \\
\hline
\end{tabular}

Now the SSIM is converted into a metrics of binary elements named as initial reachability metrics. This is developed by appropriately assigning FD, BD, RD and UD by 1 and 0 . Following rules have been applied to complete SSIM.

- If the $(i, j)$ entry in the SSIM is FD then substitute in the $(i, j)$ entry in the reachability metrics as 1 and $(j, i)$ entry as 0 .

- If the $(i, j)$ entry in the SSIM is BD then substitute in the $(i, j)$ entry in the reachability metrics as 0 and $(j, i)$ entry as 1 .

- If the $(i, j)$ entry in the SSIM is RD then substitute in the $(i, j)$ entry in the reachability metrics as 1 and $(j, i)$ entry as 1 .

- If the $(i, j)$ entry in the SSIM is UD then substitute in the $(i, \mathrm{j})$ entry in the reachability metrics as 0 and $(j, i)$ entry as 0 . 
By using these steps, the initial reachability matrix has been developed, which is shown in Table 3.Table 2 shows structural self-interaction matrix which is the initial step for the ISM and inter relationship between the flexibility factors of SSCM. Next step is the completion of final matrix based on the principle of development of initial reachability matrix stated above. Then, finally transitivity is checked in Table 4.

Table 3

Initial reachability matrix

\begin{tabular}{|c|c|c|c|c|c|c|c|c|c|c|c|c|}
\hline S. No. & Factors & 1 & 2 & 3 & 4 & 5 & 6 & 7 & 8 & 9 & 10 & 11 \\
\hline 1 & Product flexibility & 1 & 1 & 1 & 1 & 0 & 0 & 1 & 0 & 1 & 1 & 0 \\
\hline 2 & Sourcing flexibility & 1 & 1 & 0 & 1 & 1 & 0 & 0 & 0 & 1 & 1 & 0 \\
\hline 3 & Routing flexibility & 0 & 0 & 1 & 1 & 1 & 1 & 1 & 1 & 0 & 0 & 0 \\
\hline 4 & Trans-shipment flexibility & 0 & 1 & 0 & 1 & 0 & 0 & 0 & 0 & 0 & 0 & 0 \\
\hline 5 & Delivery flexibility & 1 & 0 & 1 & 1 & 1 & 1 & 1 & 0 & 0 & 0 & 0 \\
\hline 6 & Distribution flexibility & 0 & 0 & 0 & 1 & 1 & 1 & 1 & 0 & 0 & 0 & 0 \\
\hline 7 & Responsiveness flexibility & 0 & 1 & 0 & 1 & 0 & 0 & 1 & 1 & 1 & 1 & 1 \\
\hline 8 & Postponement flexibility & 0 & 0 & 0 & 0 & 0 & 1 & 0 & 1 & 0 & 0 & 0 \\
\hline 9 & $\begin{array}{l}\text { Waste and recycling } \\
\text { flexibility }\end{array}$ & 0 & 0 & 0 & 0 & 0 & 0 & 0 & 0 & 1 & 0 & 0 \\
\hline 10 & Natural resource flexibility & 0 & 0 & 0 & 0 & 0 & 0 & 0 & 0 & 1 & 1 & 0 \\
\hline 11 & Launch flexibility & 0 & 1 & 0 & 0 & 0 & 0 & 0 & 0 & 0 & 0 & 1 \\
\hline
\end{tabular}

In Table 3, initial reachability matrix is presented by changing the flexibility factors relationship in binary numbers of 0 's and 1's. Since it is found that some more relationships among the factors are relevant for the final reachability matrix, Table 4 is prepared by considering the transitivity which is represented by $1^{*}$. The final reachability matrix is given in Table 4 . Here, the transitivity is taken into account and established the relationship between different factors. If a factor $A$ leads to another factor $B$ and factor $B$ leads to a third factor $C$, as per the rule of transitivity $A$ leads to $C$. In other words, if $A$ leads to $B$ and $B$ lead to $C$, then $A$ leads to $C$. Through this step the final reachability matrix is developed (Table 4).

Table 4

Final reachability matrix with transitivity

\begin{tabular}{|c|c|c|c|c|c|c|c|c|c|c|c|c|}
\hline S. No. & Factors & 1 & 2 & 3 & 4 & 5 & 6 & 7 & 8 & 9 & 10 & 11 \\
\hline 1 & Product flexibility & 1 & 1 & 1 & 1 & $1 *$ & $1 *$ & 1 & $1 *$ & 1 & 1 & $1^{*}$ \\
\hline 2 & Sourcing flexibility & 1 & 1 & $1 *$ & 1 & 1 & $1 *$ & $1 *$ & 0 & 1 & 1 & 0 \\
\hline 3 & Routing flexibility & 0 & 0 & 1 & 1 & 1 & 1 & 1 & 1 & 0 & 0 & 0 \\
\hline 4 & Trans-shipment flexibility & 0 & 1 & 0 & 1 & 0 & 0 & 0 & 0 & 0 & 0 & 0 \\
\hline 5 & Delivery flexibility & 1 & 0 & 1 & 1 & 1 & 1 & 1 & 0 & 0 & 0 & 0 \\
\hline 6 & Distribution flexibility & 0 & 0 & 0 & 1 & 1 & 1 & 1 & $1 *$ & $1 *$ & $1 *$ & $1 *$ \\
\hline 7 & Responsiveness flexibility & 0 & 1 & 0 & 1 & 0 & $1 *$ & 1 & 0 & 1 & 1 & 1 \\
\hline 8 & Postponement flexibility & 0 & 0 & 0 & 0 & 0 & 1 & 0 & 0 & 0 & 0 & 0 \\
\hline 9 & Waste and recycling flexibility & 0 & 0 & 0 & 0 & 0 & 0 & 0 & 0 & 1 & 0 & 0 \\
\hline 10 & Natural resource flexibility & 0 & 0 & 0 & 0 & 0 & 0 & 0 & 0 & 1 & 1 & 0 \\
\hline 11 & Launch flexibility & 0 & 1 & 0 & 0 & 0 & 0 & 0 & 0 & 0 & 0 & 1 \\
\hline
\end{tabular}

Table 5 conical matrix shows the inter relations of all flexibility factors. The driving power and dependence power are calculated by summing up the number of rows and columns respectively. These driving power and dependence helps to classify the factors into four clusters namely autonomous, dependent, linkage and independent. These four clusters are determined by the separation of antecedent set and reachability set. From these sets intersection set tables are prepared and flexibility factors are identified at each level. In next step, based on the initial reachability matrix, a digraph including transitivity links is obtained. This is generated by nodes and lines of edges. After removing the indirect links, a final digraph is developed. In this development, the top level flexibility factor is positioned at the top of the digraph and second level flexibility factor is placed at second position and so on, until the bottom level is placed at the lowest position in the digraph. Then digraph obtained is converted into the T-ISM based model by converting the node into flexibility factors as shown in Fig. 1. 


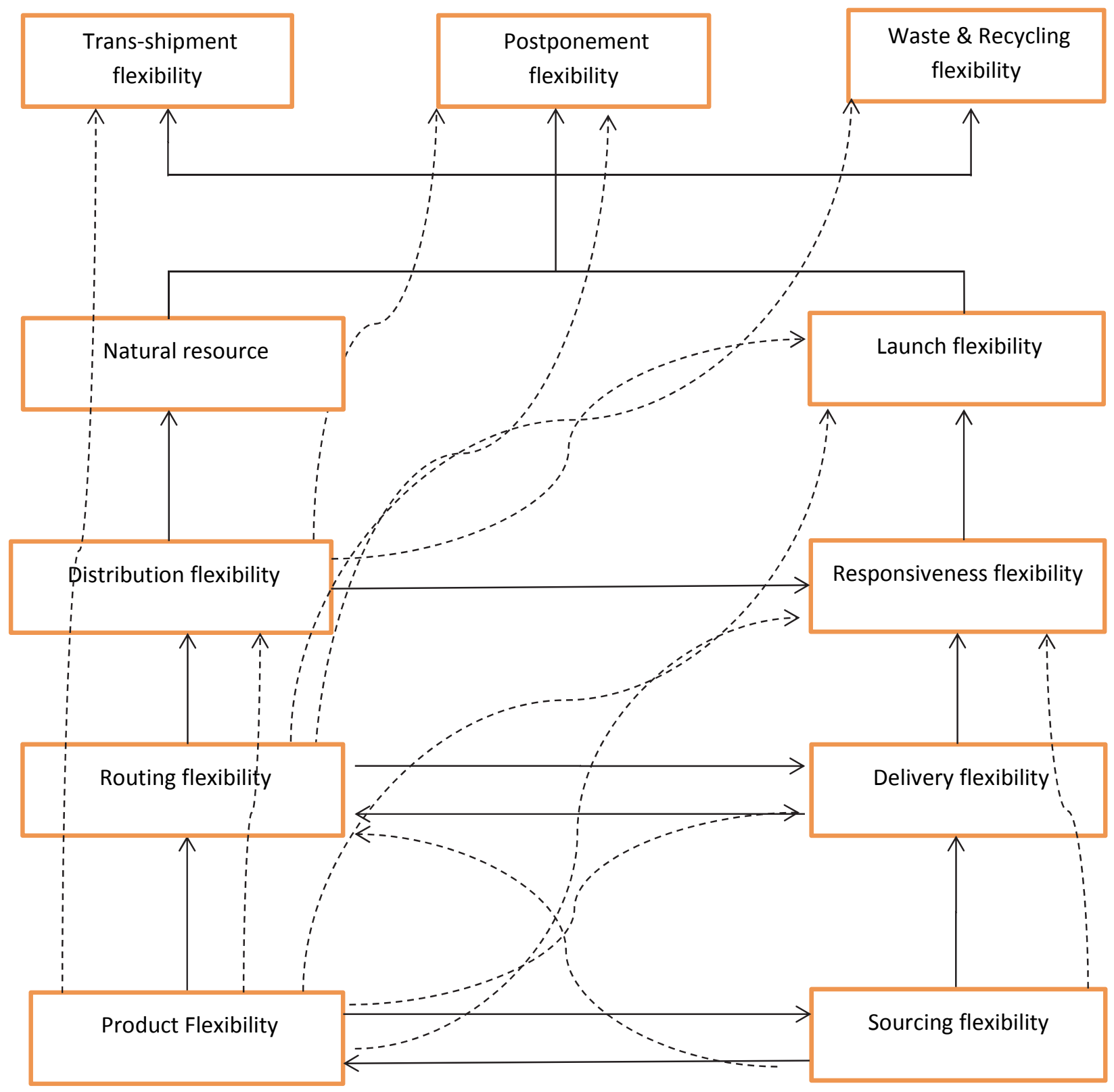

Fig. 1. T-ISM based diagraph showing the relationship among flexibility factors

\section{Table 5}

Conical matrix

\begin{tabular}{lllllllllllll}
\hline Flexible factors & 4 & 8 & 9 & 10 & 11 & 6 & 7 & 3 & 5 & 1 & 2 & Driving power \\
\hline 4 & 1 & 0 & 0 & 0 & 0 & 0 & 0 & 0 & 0 & 0 & 1 & 2 \\
8 & 0 & 1 & 0 & 0 & 0 & 1 & 0 & 0 & 0 & 0 & 0 & 2 \\
9 & 0 & 0 & 1 & 0 & 0 & 0 & 0 & 0 & 0 & 0 & 0 & 1 \\
10 & 0 & 0 & 1 & 1 & 0 & 0 & 0 & 0 & 0 & 0 & 0 & 2 \\
11 & 0 & 0 & 0 & 0 & 1 & 0 & 0 & 0 & 0 & 0 & 1 & 2 \\
6 & 1 & 1 & 1 & 1 & 1 & 1 & 1 & 0 & 1 & 0 & 0 & 8 \\
7 & 1 & 1 & 1 & 1 & 1 & 1 & 1 & 0 & 0 & 0 & 1 & 8 \\
3 & 1 & 1 & 0 & 0 & 0 & 1 & 1 & 1 & 1 & 0 & 0 & 6 \\
5 & 1 & 0 & 0 & 0 & 0 & 1 & 1 & 1 & 1 & 1 & 0 & 6 \\
1 & 1 & 1 & 1 & 1 & 1 & 1 & 1 & 1 & 1 & 1 & 1 & 11 \\
2 & 1 & 0 & 1 & 1 & 0 & 1 & 1 & 1 & 1 & 1 & 1 & 9 \\
\hline Dependence power & 7 & 5 & 6 & 5 & 4 & 7 & 6 & 4 & 5 & 3 & 5 & \\
\hline
\end{tabular}


Table 6

Iteraton-1

\begin{tabular}{llll}
\hline Factors & Reachability set & Antecedent set & Intersection \\
\hline $\mathbf{1}$ & $1,2,3,4,5,6,7,8,9,10,11$ & $1,2,5$ & $1,2,5$ \\
$\mathbf{2}$ & $1,2,3,4,5,6,7,9,10$ & $1,2,4,7,11$ & $1,2,4,7$ \\
$\mathbf{3}$ & $3,4,5,6,7,8$ & $1,2,3,5$ & 3,5 \\
$\mathbf{4}$ & 2,4 & $1,2,3,4,5,6,7$ & 2,4 \\
$\mathbf{5}$ & $1,3,4,5,6,7$ & $1,2,3,5,6$ & $1,3,5,6$ \\
$\mathbf{6}$ & $4,5,6,7,8,9,10,11$ & $1,2,3,5,6,7,8$ & $5,6,7,8$ \\
$\mathbf{7}$ & $2,4,6,7,8,9,10,11$ & $1,2,3,5,6,7$ & $2,6,7$ \\
$\mathbf{8}$ & 6,8 & $1,3,6,7,8$ & 6,8 \\
$\mathbf{9}$ & 9 & $1,2,6,7,9,10$ & 9 \\
$\mathbf{1 0}$ & 9,10 & $1,2,6,7,10$ & 10 \\
$\mathbf{1 1}$ & 2,11 & $1,6,7,11$ & 11 \\
\hline
\end{tabular}

Table 7

Iteration 2

\begin{tabular}{llll}
\hline Factors & Reachability set & Antecedent set & Intersection \\
\hline $\mathbf{1}$ & $1,3,5,7,10,11$ & 1,5 & 1,5 \\
$\mathbf{2}$ & $1,3,5,7,10$ & $1,7,11$ & 1,7 \\
$\mathbf{3}$ & $3,5,7$ & $1,3,5$ & 3,5 \\
$\mathbf{5}$ & $1,3,5,7$ & $1,3,5$ & $1,3,5$ \\
$\mathbf{6}$ & $5,7,10,11$ & $1,3,5,7$ & 5,7 \\
$\mathbf{7}$ & $7,10,11$ & $1,3,5,7$ & 7 \\
$\mathbf{1 0}$ & 10 & $1,7,10$ & 10 \\
$\mathbf{1 1}$ & 11 & $1,7,11$ & 11 \\
\hline
\end{tabular}

Table 8

Iteration 3

\begin{tabular}{llll}
\hline Factors & Reachability set & Antecedent set & Intersection \\
\hline $\mathbf{1}$ & $1,3,5,7$ & 1,5 & 1,5 \\
$\mathbf{2}$ & $1,3,5,7$ & 1,7 & 1,7 \\
$\mathbf{3}$ & $3,5,7$ & $1,3,5$ & 3,5 \\
$\mathbf{5}$ & $1,3,5,7$ & $1,3,5$ & $1,3,5$ \\
$\mathbf{6}$ & 5,7 & $1,3,5,7$ & 5,7 \\
$\mathbf{7}$ & 7 & $1,3,5,7$ & 7 \\
\hline
\end{tabular}

Table 9

Iteration 4

\begin{tabular}{|c|c|c|c|c|}
\hline Factors & Reachability set & Antecedent set & Intersection & Levels \\
\hline 1 & 1,3 & 1 & 1 & \\
\hline 2 & 1,3 & 1 & 1 & \\
\hline 3 & 3 & 1,3 & 3 & IV \\
\hline 5 & 1,3 & 1,3 & 1,3 & IV \\
\hline
\end{tabular}

Table 10

Iteration 5

\begin{tabular}{lllll}
\hline Factors & Reachability set & Antecedent set & Intersection & Levels \\
\hline $\mathbf{1}$ & 1,3 & 1 & 1 & $\mathrm{~V}$ \\
\hline $\mathbf{2}$ & 1,3 & 1 & 1 & $\mathrm{~V}$ \\
\hline
\end{tabular}

\section{Results and Discussions}

To achieve the objectives, ISM-based model and its upgraded version TISM model have been developed in order to understand the interactions among the flexibility factors in SSCM. In this research it is found that product flexibility and sourcing flexibility are the most important flexibility factors for sustainable management in supply chain. All the flexibility factors are put at different levels, so as to get the interrelationship between them. Level partition is done by considering reachability set, antecedent set and intersection set. There are five partition levels. The inter relationship of factors are found out. From the T-ISM based diagraph, in first level factors the removal of the top most factors will not affect the system. Three factors are removed from first level. The second level factors are natural resource and launch flexibility. Distribution flexibility and responsiveness flexibility comes in 
third level. In the fourth and fifth level routing and delivery, product and sourcing flexibility comes respectively. All the factors are related to each other and influences to one another. Product flexibility and sourcing flexibility are the root cause for all the flexibility in sustainable management.

Table 11

Cluster Graph

\begin{tabular}{|c|c|c|c|c|c|c|c|c|c|c|c|c|}
\hline \multirow{12}{*}{ 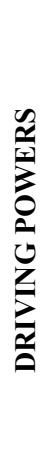 } & 11 & & & 1 & & & & & & & & \\
\hline & 10 & & \multirow{2}{*}{\multicolumn{2}{|c|}{ IV }} & & & & & \multirow{2}{*}{\multicolumn{2}{|c|}{ III }} & & \\
\hline & 9 & & & & & 2 & & & & & & \\
\hline & 8 & & & & & & 7 & 6 & & & & \\
\hline & 7 & & & & & & & & & & & \\
\hline & 6 & & & & 3 & 5 & & & & & & \\
\hline & 5 & & & & & & & & & & & \\
\hline & 4 & & \multirow{2}{*}{\multicolumn{2}{|c|}{ I }} & & & & & \multirow{2}{*}{\multicolumn{2}{|c|}{ II }} & & \\
\hline & 3 & & & & & & & & & & & \\
\hline & 2 & & & & 11 & 8,10 & & 4 & & & & \\
\hline & 1 & & & & & & 9 & & & & & \\
\hline & & 1 & 2 & 3 & 4 & 5 & 6 & 7 & 8 & 9 & 10 & 11 \\
\hline
\end{tabular}

The driver-dependence matrix diagram helps to classify and collect flexibility factors in terms of driving power and dependence power. The driver-dependence matrix diagram (Table 11) indicates that postponement flexibility, natural resource flexibility and launch flexibility are the autonomous factors in first quadrant. These factors have weak drivers and weak dependents and do not any influence on the system. Trans-shipment flexibility and waste \& recycling flexibility are the dependent factors in second quadrant. These factors have weak drivers but strongly depend on one another. Distribution flexibility and responsiveness flexibility are the linkage factors in third quadrant. These factors have strong driving power as well as high dependencies. Product flexibility, sourcing flexibility and routing flexibility are the independent factors in fourth quadrant. They have strong driving power and less dependent on other factors. Therefore, these are strong drivers and may be treated as the root causes of all the factors. These factors may be treated as the 'key flexible factors' for affecting the sustainable supply chain. This cluster graph along with T-ISM model gives valuable decision-making insight and implications about the relative importance and the interdependence between the factors of interest. This will help to improve organization sustainability and thus will help in improving customer satisfaction.

\section{Conclusions and future directions}

The results obtain in this study help in identifying and executing the factors which are helpful for sustainable management. The main factors product flexibility and sourcing flexibility are helpful for the adaptation of sustainability in supply chain. Once the product flexibility and sourcing flexibility implemented the firm can have benefits in whole sustainable supply chain management. In a current volatile market scenario, flexibility in sustainable supply chain is very much necessary to compete with global market players. Mostly companies implement sustainability without considering their capabilities and limitations. Self-examination is very much necessary for implementing flexibility in sustainable supply chain. These are the essential factors of flexibility and try to focus more on these factors. But the results of present work show the factors such as 'product flexibility' and 'sourcing flexibility' have higher driving power than other factors and are considered to be the key factors. This is because it is true from the practical point of view, if the management does not have better sources for production and a strong desire for the successful implementation of flexibility, other technological techniques will have no much important. Therefore, T-ISM of the factors strengthens the practical views of manufacturing managers and depicts a clear picture about the significance of different factors. In this way, different factors can be identified and dealt with utmost care for the successful implementation of flexibility. The factors with high driving power are of strategic orientation. On the other hand, dependent factors are of operation and performance orientation. Hence, superior performance of flexibility can be achieved continuously by improving the driving factors. 


\section{Limitations}

One major limitation of this T-ISM based model is highly dependence on the judgements of the expert opinion, so the model must be validated. In present research, only 11 flexibility factors in sustainable supply chain are identified. This research can further be extended by identifying the other factors and other issues in sustainable supply chain. This research can further be conducted on specific industries. Structural equation modeling can also be used to validate the T-ISM based model. A graph theoretic approach can also be used to find the effectiveness index of flexibility factors. Further this work can also be extended using W-ISM.

\section{References}

Amalnick, M., \& Saffar, M. (2017). An integrated approach for supply chain assessment from resilience engineering and ergonomics perspectives. Uncertain Supply Chain Management, 5(3), 159-168.

Azzone, G. \& Bertele, U. (1989). Measuring the economic effectiveness of flexible automation: a new approach, International Journal of Production Research, 27(5),735-746.

Beskese, A., Kahraman, C. \& Irani, Z. (2004). Quantification of flexibility in advanced manufacturing systems using fuzzy concept. International Journal of Production Economics, 89(4), 45-56.

Browne, J., Dubois, D., Rathmill, K., Sethi, S. P., \& Stecke, K. E. (1984). Classification of flexible manufacturing systems. The FMS magazine, 2(2), 114-117.

Buzacott, J. A. (1982, October). The fundamental principles of flexibility in manufacturing systems. In Proceedings of the 1st international conference on flexible manufacturing systems (pp. 13-22). North Holland Publishing Co.

Bottani, E., Montanari, R., \& Rinaldi, M. (2015). How many to produce? The impact of machine flexibility on the performance of a supply chain. International Journal of Supply Chain and Inventory Management, $1(1), 62-90$.

Chan, H. K., \& Chan, F. T. (2010). Comparative study of adaptability and flexibility in distributed manufacturing supply chains. Decision Support Systems, 48(2), 331-341.

Chand, M., Raj, T., \& Shankar, R. (2014). Analysing the operational risks in supply chain by using weighted interpretive structure modelling technique. International Journal of Services and Operations Management, 18(4), 378-403.

Chand, M., Raj, T., \& Shankar, R. (2015). Weighted-ISM technique for analysing the competitiveness of uncertainty and risk measures in supply chain. International Journal of Logistics Systems and Management, 21(2), 181-198.

Chen, I. J., \& Chung, C. H. (1996). An examination of flexibility measurements and performance of flexible manufacturing systems. International Journal of Production Research, 34(2), 379-394.

Chidambaranathan, S., Muralidharan, C., \& Deshmukh, S. G. (2009). Analyzing the interaction of critical factors of supplier development using Interpretive Structural Modeling - an empirical study. The International Journal of Advanced Manufacturing Technology, 43(11), 1081-1093.

Corrêa, H. L. (1994). Linking Flexibility, Uncertainty and Variability in Manufacturing Systems: Managing un-planned change in the automative industry. Avebury.

Dangayach, G. S., \& Deshmukh, S. G. (2001). Manufacturing strategy perspective on flexibility: a case of select Indian companies. Global Journal of Flexible Systems Management, 2(2), 21-30.

Beamon, B. M. (1999). Measuring supply chain performance. International journal of operations \& production management, 19(3), 275-292.

Day, G. S. (1994). The capabilities of market-driven organizations. the Journal of Marketing, 37-52.

Dixon, J. R. (1990). The new performance challenge: Measuring operations for world-class competition. Irwin Professional Pub.

Dong, L., \& Rudi, N. (2004). Who benefits from transshipment? Exogenous vs. endogenous wholesale prices. Management Science, 50(5), 645-657.

Dubey, R., \& Ali, S. S. (2014). Identification of flexible manufacturing system dimensions and their interrelationship using total interpretive structural modelling and fuzzy MICMAC analysis. Global Journal of Flexible Systems Management, 15(2), 131-143. 
Elcio M. T., \& Giménez C. (2007). Drivers and sources of supply flexibility: An exploratory study. International Journal of Operations \& Production Management. 27(10), 1115-1136.

Esmaeilikia, M., Fahimnia, B., Sarkis, J., Govindan, K., Kumar, A., \& Mo, J. (2016). Tactical supply chain planning models with inherent flexibility: definition and review. Annals of Operations Research, 244(2), 407-427.

Gerwin, D. (1987). An agenda for research on the flexibility of manufacturing processes. International Journal of Operations \& Production Management, 7(1), 38-49.

Tennant, S., \& Fernie, S. (2013). Organizational learning in construction supply chains. Engineering, Construction and Architectural Management, 20(1), 83-98.

Goyal, M., \& Netessine, S. (2007). Strategic technology choice and capacity investment under demand uncertainty. Management Science, 53(2), 192-207.

Helmuth, C. A., Craighead, C. W., Connelly, B. L., Collier, D. Y., \& Hanna, J. B. (2015). Supply chain management research: Key elements of study design and statistical testing. Journal of Operations Management, 36, 178-186.

George, J. P., \& Pramod, V. R. (2014). An interpretive structural model (ISM) analysis approach in steel re rolling mills (SRRMS). Int. J. Res. Eng. Technol, 2(4), 161-174.

Kausar, K., Garg, D., \& Luthra, S. (2017). Key enablers to implement sustainable supply chain management practices: An Indian insight. Uncertain Supply Chain Management, 5(2), 89-104.

Khatwani, G., Singh, S. P., Trivedi, A., \& Chauhan, A. (2015). Fuzzy-TISM: A fuzzy extension of TISM for group decision making. Global Journal of Flexible Systems Management, 16(1), 97-112.

Khatwani, G., Singh, S. P., Trivedi, A., \& Chauhan, A. (2015). Fuzzy-TISM: A fuzzy extension of TISM for group decision making. Global Journal of Flexible Systems Management, 16(1), 97-112.

Nasim, S. (2011). Total interpretive structural modeling of continuity and change forces in e-government. Journal of Enterprise Transformation, 1(2), 147-168.

Park, C. S., \& Son, Y. K. (1988). An economic evaluation model for advanced manufacturing systems. The Engineering Economist, 34(1), 1-26.

Pramod, V. R., \& Banwet, D. K. (2010). Interpretive structural modelling for understanding the inhibitors of a telecom service supply chain. IEOM (Dhaka, Bangladesh), 9-10.

Prasad, U. C., \& Suri, R. K. (2011). Modeling of continuity and change forces in private higher technical education using total interpretive structural modeling (TISM). Global Journal of Flexible Systems Management, 12(3/4), 31.

Wadhwa, S., Saxena, A., \& Chan, F. T. S. (2008). Framework for flexibility in dynamic supply chain management. International Journal of Production Research, 46(6), 1373-1404.

Attri, R., Dev, N., \& Sharma, V. (2013). Interpretive structural modelling (ISM) approach: an overview. Research Journal of Management Sciences, 2(2), 3-8.

Singh, R. K., Garg, S. K., \& Deshmukh, S. G. (2007). Interpretive structural modelling of factors for improving competitiveness of SMEs. International Journal of Productivity and Quality Management, 2(4), 423-440.

Rao, R. V., \& Parnichkun, M. (2009). Flexible manufacturing system selection using a combinatorial mathematics-based decision-making method. International Journal of Production Research, 47(24), 6981-6998.

Rudi, N., Kapur, S., \& Pyke, D. F. (2001). A two-location inventory model with transshipment and local decision making. Management science, 47(12), 1668-1680.

Sage, A. P. (1977). Methodology for large-scale systems.

Sandbhor, S. S., \& Botre, R. P. (2014). Applying total interpretive structural modeling to study factors affecting construction labour productivity. Construction Economics and Building, 14(1), 20-31.

Saxena, J. P., Sushil, \& Vrat, P. (2006). Policy and strategy formulation: An application of flexible systems methodology. GIFT Pub.

Sethi, A. K., \& Sethi, S. P. (1990). Flexibility in manufacturing: a survey. International Journal of Flexible Manufacturing Systems, 2(4), 289-328.

Dubey, R., \& Ali, S. S. (2014). Identification of flexible manufacturing system dimensions and their interrelationship using total interpretive structural modelling and fuzzy MICMAC analysis. Global Journal of Flexible Systems Management, 15(2), 131-143. 
Shewchuk, J. P. (1999). A set of generic flexibility measures for manufacturing applications. International Journal of Production Research, 37(13), 3017-3042.

Singh, A. K., \& Sushil. (2013). Modeling enablers of TQM to improve airline performance. International Journal of Productivity and Performance Management, 62(3), 250-275.

Singh, D., Oberoi, J. S., \& Ahuja, I. S. (2011). A survey of literature of conceptual frameworks assessing supply chain flexibility. International Journal of Applied Engineering Research, 2(1), 172.

Son, Y. K., \& Park, C. S. (1990). Quantifying opportunity costs associated with adding manufacturing flexibility. The International Journal of Production Research, 28(6), 1183-1194.

Srivastava, A. K., \& Sushil. (2013). Modeling strategic performance factors for effective strategy execution. International Journal of Productivity and Performance Management, 62(6), 554-582.

Sushil, S. (2012). Interpreting the interpretive structural model. Global Journal of Flexible Systems Management, 13(2), 87-106.

Dubey, R., \& Ali, S. S. (2014). Identification of flexible manufacturing system dimensions and their interrelationship using total interpretive structural modelling and fuzzy MICMAC analysis. Global Journal of Flexible Systems Management, 15(2), 131-143.

Bhawan, V., \& Marg, S. J. S. (2005). Interpretive matrix: a tool to aid interpretation of management and social research. Global Journal of Flexible Systems Management, 6(2), 27-30.

Sushil, A. (2005). A flexible strategy framework for managing continuity and change. International Journal of Global Business and Competitiveness, 1(1), 22-32.

Tavana, M., Kaviani, M. A., Di Caprio, D., \& Rahpeyma, B. (2016). A two-stage data envelopment analysis model for measuring performance in three-level supply chains. Measurement, 78, 322-333.

Thakkar, J., Deshmukh, S. G., Gupta, A. D., \& Shankar, R. (2006). Development of a balanced scorecard: an integrated approach of interpretive structural modeling (ISM) and analytic network process (ANP). International Journal of Productivity and Performance Management, 56(1), 25-59.

De Toni, A., \& Tonchia, S. (2001). Performance measurement systems-models, characteristics and measures. International Journal of Operations \& Production Management, 21(1/2), 46-71.

Tsubone, H., \& Horikawa, M. (1999). A comparison between machine flexibility and routing flexibility. International Journal of Flexible Manufacturing Systems, 11(1), 83-101.

Upton, D.M. (1994). The management of manufacturing flexibility. California

Upton, D. (1995). What really makes factories flexible?. Harvard business review, 73(4), 74-84.

Volberda, H. W. (1996). Toward the flexible form: How to remain vital in hypercompetitive environments. Organization Science, 7(4), 359-374.

Stevenson, M., \& Spring, M. (2007). Flexibility from a supply chain perspective: definition and review. International Journal of Operations \& Production Management, 27(7), 685-713.

Warfield, J. N. (1974). Developing subsystem matrices in structural modeling. IEEE Transactions on Systems, Man, and Cybernetics, 1, 74-80.

Warfield. J, (2005). Developing interconnection matrices in structural modelling. IEEE Transactionsons on Systems, Man and Cybernetics, 4(1), 81-67.

Wasuja, S., Sagar, M., \& Sushil. (2012). Cognitive bias in salespersons in specialty drug selling of pharmaceutical industry. International Journal of Pharmaceutical and Healthcare Marketing, 6(4), 310335.

Wong, H., Cattrysse, D., \& Van Oudheusden, D. (2005). Inventory pooling of repairable spare parts with non-zero lateral transshipment time and delayed lateral transshipments. European Journal of Operational Research, 165(1), 207-218.

Xiao, Y. (2015). Flexibility measure analysis of supply chain. International Journal of Production Research, 53(10), 3161-3174.

Zhang, Q., Vonderembse, M.A. \& Lim, J. (2002). Value chain flexibility: a dichotomy of capability. International Journal of Production, 40(3), 561-583.

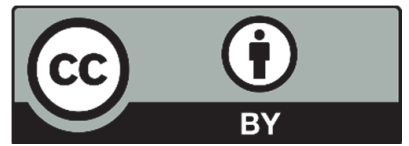

(C) 2018 by the authors; licensee Growing Science, Canada. This is an open access article distributed under the terms and conditions of the Creative Commons Attribution (CC-BY) license (http://creativecommons.org/licenses/by/4.0/). 